\title{
DAMPAK CG PADA CSRD DAN PENGARUHNYA TERHADAP PROFITABILITAS SEKTOR PERTAMBANGAN SYARIAH BEI
}

\author{
Henny Ariani ${ }^{1}$, Muhammad Umar Mai ${ }^{2}$ \\ ${ }^{1}$ Dosen MTKPS, Politeknik Negeri Bandung, Bandung, Indonesia \\ ${ }^{2}$ Mahasiswa MTKPS, Politeknik Negeri Bandung, Bandung, Indonesia \\ Email Korespondensi: henny31ariani@gmail.com
}

\begin{abstract}
The study aims to investigate the impact of corporate governance on corporate social responsibility disclosure (CSRD) and the effect of CSRD to the profitability. The samples to study was gained from annualreport of the 29 firms that listed in Sharia's critheria issued by the Bursa Efek Indonesia (BEI) in the Mining Sector Companies, from 2015 to 2019. The study will conduct by using the Partial Least Square-Structural Equation Modelling (PLS-SEM) using Warp-PLS software. The results of this study indicate that corporate governance proxied by variabels such as institutional ownership, board independent, and board of directors size have positive impact and significant to CSRD. Thus, The results have indicated that CSRD have positive impact and significant to profitability. This study contribute to the development of corporate governance's theory especially on the CSRD activities within the mining sectors companies with Sharia Critheria. Otherwise, this study gives new widen perspective to the managements and investors on the mining sectors companies with Sharia Critheria. In bound of the corporate governance, CSRD activities, and the profitability achievements.
\end{abstract}

Keywords: Corporate governance, CSRD, and profitability.

Abstrak: Penelitian ini bertujuan untuk menginvestigasi dampak corporate governance pada Corporate Social Responsibility Disclosure (CSRD) dan pengaruh CSRD terhadap profitabilitas. Sampel penelitian ini adalah perusahaan-perusahaan pertambangan kriteria Syariah yang terdaftar di Bursa Efek Indonesia selama periode 2015 hingga 2019. Metode analisis data menggunakan Partial Least Square-Structural Equation Modelling (PLS-SEM) dengan bantuan software Warp-PLS. Hasil menunjukkan bahwa corporate governance yang diproksi variabel institutional ownership, board independent, dan board of directors size berpengaruh positif dan signifikan terhadap CSRD. Selanjutnya, hasil menunjukkan bahwa CSRD berpengaruh prositif dan signifikan terhadap profitabilitas. Penelitian ini berkontribusi pada pengembangan teori corporate governance dalam kaitannya dengan aktivitas CSRD, khususnya untuk perusahaan pertambangan kriteria Syariah. Selain itu, penelitian ini memberikan tambahan wawasan bagi manajemen dan investors perusahaan pertambangan kriteria Syariah dalam kaitannya dengan corporate governance, aktivitas CSRD, dan capaian profitabilitas.

Kata Kunci: Corporate governance, CSRD, dan profitabilitas. 


\section{PENDAHULUAN}

Saat ini Corporate Social Responsibility (CSR) telah menjadi bagian yang tidak terpisahkan dari praktik bisnis perusahaan, dan telah mendapat banyak perhatian dalam literatur keuangan selama beberapa dekade terakhir (Skovgaard, 2014). Kegiatan CSR di Indonesia dilatarbelakangi dengan terbitkannya Peraturan Praktik dan Pengungkapan CSR melalui UU Perseroan Terbatas Nomor 40 tahun 2007, pasal 66 dan 74 serta UU Penanaman Modal Nomor 25 tahun 2007 yang mengatur bahwa setiap penanaman modal untuk ikut serta melaksanakan program CSR. Sejak itu, perusahaan-perusahaan public di Indonesia mulai mendedikasikan bagian dari laporan tahunan (annual report) dan laman website mereka untuk mengungkapkan kegiatan-kegiatan CSR. Hal ini menunjukkan begitu pentingnya perusahaan-perusahaan dalam melakukan dan mengungkapkan kegiatan CSR untuk kelangsungan hidup mereka (Servaes \& Tamayo, 2013).

Lebih dari dua dekade yang lalu, Epstein \& Freedman (1994) menjelaskan bahwa CSR diyakini dapat memberikan keunggulan bersaing, karena investors dalam mengambil keputusan investasi mereka tidak lagi hanya melihat kinerja keuangan perusahaan. Para investor lebih tertarik pada informasi sosial yang diungkapkan dalam laporan tahunan perusahaan. Selanjutnya, berkembangnya isu tentang pentingnya CSR bagi pelaku bisnis, menyebabkan studi tentang CSR telah banyak dilakukan di berbagai belahan dunia beberapa dekade terakhir (Kansal et al., 2014). Studi dibidang CSR saat ini telah bergeser fokus kajian dari cara mengukur CSR Disclosure (CSRD) menjadi eksplorasi terhadap faktor-faktor yang mempengaruhinya (Khlif \& Souissi, 2010).

Para peneliti di lingkungan akademisi telah melakukan upaya keras untuk menggali faktor finansial dan non finansial sebagai determinan kegiatan sosial dan lingkungan yang dilakukan perusahaan. Faktor-faktor tersebut adalah: ukuran perusahaan (Haniffa \& Cooke, 2005; Said et al., 2009), kinerja keuangan (Waddock \& Graves, 1997; Oeyono et al., 2011), umur perusahaan (Cormier et al., 2005; Shafiqur, 2011), dan karakteristik dewan direksi (Hossain \& Reaz, 2007). Namun, berbagai penelitian determinan CSRD itu sampai saat ini melaporkan temuan yang tidak konsisten. Hasil penelitian profitabilitas sebagai determinan CSRD memberikan kesimpulan yang tidak meyakinkan. Beberapa peneliti gagal menemukan hubungan apapun antara profitabilitas dan CSRD (Aras \& Kutlu, 2010; Esa \& Ghazali, 2012; Rahman et al., 2017). Peneliti lain menemukan hubungan positif antara profitabilitas dan CSRD (Jaffar et al., 2007; Oeyono et al., 2011). Sedangkan, Derksen (2013) menemukan hubungan negatif profitabilitas dengan CSRD. Literatur keuangan dan hasil-hasil studi sebelumnya menjelaskan bahwa ukuran perusahaan berpengaruh positif terhadap CSRD (Artiach et al., 2010; (Kansal et al., 2014); Crisostomo dan Oliveira, 2015). Hal ini dapat dipahami karena perusahaan-perusahaan besar cenderung mendapat perhatian lebih dari masyarakat dan berada di bawah tekanan yang kuat untuk menunjukkan tanggung jawab sosial mereka.

Perkembangan selanjutnya para peneliti lebih mengarahkan pehatian mereka pada corporate governance sebagai faktor terpenting dalam mendorong perusahaan untuk mekakukan CSR. Namun, seperti studi yang menempatkan firm specific factors sebagai 
determinan CSR, beberapa studi inipun menemukan bukti empiric yang beragam tentang dampak corpoarate governance pada CSRD. Sebagian besar hasil penelitian tersebut membuktikan hubungan positif antara corporate governance yang diukur board independent dan CSRD (De Villiers et al., 2011; Post et al., 2011; Jizi et al., 2014). Namun, Donnelly dan Mulcany (2008) menemukan hubungan yang negatif, sedangkan Said et al. (2009) membuktikan bahwa antara board independent dan CSRD tidak ada hubungan. Penelitian hubungan corporate governance yang diukur institutional ownership dengan CSRD sebagian besar menyimpulkan hubungan yang positif (Mahoney dan Roberts, 2007; Oh et al., 2011). Namun, Bartkus et al. (2002) di USA membuktikan bahwa institutional ownership berpengaruh negatif terhadap CSRD. Selain itu, penelitian yang menguji hubungan antara CSRD dan kinerja perusahaan telah banyak dilakukan, tetapi penelitian-penelitian ini melaporkan temuan yang beragam. Penelitian Nguyen (2015) di Vietnam dan Adeneye (2015) di Inggris membuktikan bahwa CSR berpengaruh positif terhadap kinerja perusahaan. Namun, penelitian Reddy dan Gordon (2010) serta Cui et al. (2012) menemukan hubungan yang negatif antara CSRD dan kinerja perusahaan. Temuan lainnya dilaporkan Sabbaghi dan Xu (2013) serta Chen dan Lee (2017) di Taiwan yang membuktikan bahwa CSRD tidak berpengaruh terhadap kinerja perusahaan. Penelitian Servaes dan Tamayo (2013) menyimpulkan bahwa CSRD dan kinerja perusahaan memiliki hubungan yang positif pada perusahaan dengan kesadaran pelanggan yang tinggi, sedangkan pada perusahaan dengan kesadaran pelanggan rendah, hubungan tersebut negative dan/ atau tidak signifikan.

Berkaitan dengan CSRD, Sari (2015) menjelaskan bahwa industri pertambangan di Indonesia memiliki dampak positif dan negatif bagi masyarakat dan negara. Dampak positif dari industri pertambangan antara lain adalah menciptakan lapangan pekerjaan, hasil produksi pertambangan dapat digunakan untuk memenuhi permintaan pasar domestik maupun internasional, sehingga hasil ekspor tambang dapat meningkatkan pendapatan dan pertumbuhan perekonomian negara. Industri pertambangan juga dapat menarik investasi asing untuk menanamkan modalnya di Indonesia. Namun, dari sisi lingkungan hidup, pertambangan dianggap paling merusak dibanding kegiatan eksploitasi sumberdaya alam lainnya. Pertambangan dapat mengubah bentuk bentang alam, merusak dan atau menghilangkan vegetasi, menghasilkan limbah tailing, serta menguras air tanah dan air permukaan. Jika tidak direhabilitasi, lahan-lahan bekas pertambangan tersebut akan membentuk kubangan raksasa dan hamparan tanah gersang yang bersifat asam (https://kompasiana.com). Selanjutnya, untuk mengatasi dampak negatif tersebut, maka setiap perusahaan harus menjalankan CSR, dan CSR tersebut harus diterapkan dengan prinsip pembangunan berkelanjutan, yaitu untuk memenuhi kebutuhan sekarang tanpa harus mengorbankan kebutuhan generasi masa depan (Sari, 2015).

Perusahaan sektor pertambangan di Bursa Efek Indonesia (BEI) terbagi menjadi dua kelompok, yaitu sektor pertambangan kriteria syariah dan non-syariah. Sektor pertambangan kriteria syariah ditetapkan berdasarkan Fatwa Dewan Syari'ah Nasional Majelis Ulama Indonesia (DSN-MUI). Keputusan DSN-MUI Nomor 40/DSNMUI/X/2003 tentang Pasar Modal, salah satunya menyebutkan bahwa perusahaan publik yang sahamnya masuk kriteria syariah harus memiliki jenis usaha, produk barang 
atau jasa yang diberikan dan akad serta cara pengelolaannya tidak bertentangan dengan prinsip-prinsip syariah Islam. Berdasarkan masalah yang dikemukakan, penelitian ini bertujuan untuk menguji pengaruh corporate governance terhadap CSRD, dan pengaruh CSRD terhadap profitabilitas. Penelitian ini dilakukan pada sektor pertam-bangan kriteria syariah yang tercatat di BEI selama periode 2015 hingga 2019.

\section{TINJAUAN PUSTAKA}

CSR berkaitan dengan bagaimana perusahaan mengelola bisnisnya untuk dapat menghasilkan efek positif bagi masyarakat. Dengan demikian, perusahaan perlu memperhitungkan kualitas manajemennya, sifat, dan kuantitas dampaknya terhadap masyarakat di berbagai bidang (Baker, 2004). Agency theory membahas masalah yang muncul di perusahaan karena pemisahan antara pemilik (principle) dan manajer (agent) serta menjelaskan cara untuk mengatasi masalah ini (Panda \& Leepsa, 2017). Corporate governance dibangun dan dikembangkan berdasarkan agency theory. Corporate governance adalah sistem yang tidak hanya meningkatkan hubungan antara pemegang saham, manajer, dan investor, tetapi memastikan bahwa penyediaan sumber daya yang tepat di antara para pengguna yang bersaing (Al-ahdal et al., 2020). Teori agency menjelaskan perusahaan yang melakukan pengungkapan informasi tanggung jawab sosial bertujuan untuk membangun image positif dan mendapatkan perhatian masyarakat. Ketika perusahaan menghadapi biaya pengawasan dan biaya kontrak yang rendah dan visibilitas politis yang tinggi cenderung mengungkapkan informasi pertanggungjawaban sosialnya. Dengan demikian, pengungkapan informasi pertanggungjawaban sosial berhubungan positif dengan kinerja sosial, kinerja ekonomi, visibilitas politis, dan berhubungan negatif dengan biaya pengawasan dan biaya kontrak (agency cost). Studi Barnea dan Rubin (2010) menggunakan agency theory menguji hubungan principal dan agent dengan aktivitas CSR. Mereka menyimpulkan bahwa kinerja sosial yang lebih tinggi berhubungan dengan tingkat pengeluaran CSR yang lebih besar.

\section{Institutional Ownership and Corporate Social Responsibility}

Kepemilikan institusional adalah kepemilikan saham oleh pihak-pihak yang berbentuk institusi. Institusi biasanya menguasai sebagian besar saham karena sumber dayanya lebih besar dari pemegang saham lainnya. Kepemilikan institusional yang tinggi akan menyebabkan upaya pengawasan yang lebih besar oleh investor sehingga dapat menghambat perilaku oportunistik manajer. Selain itu, investor cenderung memiliki hak untuk memantau pengambilan keputusan untuk kebutuhan operasional perusahaan serta keputusan mengenai tanggung jawab sosial yang akan dilakukan oleh perusahaan. Kekayaan pemegang saham memiliki hubungan dengan CSR perusahaan, oleh karena itu, mengamati keterlibatan pemegang saham dalam kebijakan CSR menjadi menarik dan penting bagi investor institusi (Chen et al., 2019; Kim et al., 2019). Salah satu saluran terpenting di mana para pemegang saham dapat mempengaruhi CSR perusahaan adalah dengan menggunakan hak suara mereka untuk mendorong perusahaan guna melakukan dan mengungkapkan semuak aktivitas CSR (Arlbjørn et al., 2008). Studi Meng \& Wang (2020) pada perusahaan yang tercatat di NYSE, AMEX dan NASDAQ, dan studi 
Trisnawati et al. (2019) pada perusahaan properti, real estate dan konstruksi bangunan yang terdaftar di Bursa Efek Indonesia melaporkan bahwa institutional ownership berpengaruh positif terhadap CSRD. Oleh karena itu, hipotesis yang diajukan adalah:

H1: Institutional ownership berdampak positif pada CSRD.

\section{Independent Board of Commissioners and Corporate Social Responsibility}

Teori pemangku kepentingan menjelaskan bahwa kurangnya kepentingan material dan posisi non-keuangan dari komisaris independen menyebabkan mereka mengejar kepentingan semua pemangku kepentingan. Merkea memaksa manajemen untuk mengungkapkan lebih banyak informasi terkait keberlanjutan dan untuk meningkatkan citra perusahaan dengan berfokus pada isu-isu lingkungan dan sosial (Rao et al., 2012). Studi sebelumnya tidak meyakinkan mengenai hubungan antara independensi dewan dan pelaporan CSR. Misalnya, menggunakan data bank Kenya, Barako dan Brown (2008) membuktikan tingkat independen dewan secara signifikan meningkatkan pengungkapan CSR. Jizi et al. (2013) mendokumentasikan bahwa proporsi yang lebih tinggi dari dewan independen mengarah ke pengungkapan CSR yang lebih luas oleh bank-bank AS. Pada bank Bangladesh, Khan (2010) melaporkan bahwa proporsi yang lebih tinggi dari dewan independen mengarah ke tingkat yang lebih besar dari informasi pelaporan CSR. Kilıc et al. (2015) menemukan hubungan positif antara independensi dewan dan pengungkapan CSR bank Turki. Namun, Hossain dan Reaz (2007) tidak menemukan hubungan antara independensi dewan dan tingkat pengungkapan CSR oleh perusahaan perbankan India. Studi Ghabayen et al. (2016) melaporkan bahwa independensi dewan secara negatif terkait dengan pengungkapan CSR bank Yordania. Studi terbaru yang dilakukan Celentano et al. (2020) melaporkan bahwa dewan komisaris independen berpengaruh positif terhadap CSRD. Oleh karena itu, hipotesis yang diajukan adalah:

H2. Independensi dewan komisaris berdampak positif pada CSRD.

\section{Board of Directors Size and Corporate Social Responsibility}

Ukuran dewan dapat mempengaruhi tingkat pengungkapan sukarela dan proses pengambilan keputusan (Lone et al., 2016). Dari sudut pandang teori ketergantungan sumber daya, dewan yang lebih besar cenderung memiliki dampak positif pada praktik pelaporan perusahaan karena anggota dewan dapat membawa berbagai nilai, pengetahuan, ide, dan perspektif ke organisasi mana pun (Pfeffer \& Salancik, 2003). Dari perspektif teori pemangku kepentingan, dewan yang lebih besar, yang terdiri dari anggota dari kelompok pemangku kepentingan yang beragam, menawar untuk pelaporan keuangan yang lebih wajib dan pengungkapan sukarela untuk memenuhi kebutuhan dan kepentingan mereka sendiri (Hahn et al., 2015). Studi sebelumnya tentang hubungan antara ukuran dewan dan pengungkapan CSR telah memberikan hasil yang beragam. Menggunakan data bank komersial besar AS, Jizi et al. (2013) memberikan bukti bahwa ukuran dewan memiliki dampak positif pada pengungkapan CSR. Demikian pula, Ghabayen et al. (2016) melaporkan bahwa bank dengan dewan yang lebih besar mengungkapkan lebih banyak informasi tentang kegiatan CSR di sektor perbankan Yordania. Namun, Kilıc, et al. (2015) berpendapat bahwa ukuran dewan tidak memiliki 
dampak dari praktik pengungkapan CSR di bank Turki. Studi terbaru yang dilakukan oleh Tran et al. (2020) di bank komersial Vietnam membuktikan bawa ukuran dewan berpengaruh positif terhadap CSRD. Oleh karena itu, hipotesis yang diajukan adalah:

H3. Ukuran dewan direktur berdampak positif pada CSRD.

\section{Corporate Social Responsibility and Profitability}

Karya-karya penelitian yang didukung oleh ekonomi neoklasik mengungkapkan bahwa CSR tidak perlu karena dapat meningkatkan biaya perusahaan, menempatkan perusahaan dalam posisi kerugian kompetitif dengan pesaingnya (Friedman, 1970; Aupperle et al., 1985; McWilliams \& Siegel, 1997; Jensen, 2002). Berdasarkan agency theory, beberapa penelitian juga berpendapat bahwa pengeluaran sumber daya perusahaan yang berharga untuk terlibat dalam CSR hanya menghasilkan manfaat manajerial yang signifikan daripada manfaat finansial bagi pemegang saham perusahaan (Brammer \& Millington, 2008). Namun, sebaliknya para peneliti lainnya berpendapat bahwa melakukan kegiatan CSR dapat memiliki efek positif pada kinerja perusahaan dengan menyediakan akses yang lebih baik ke sumber daya yang berharga (Cochran \& Wood, 1984), menarik dan mempertahankan karyawan berkualitas lebih tinggi (Turban \& Greening, 1997; Greening dan Turban , 2000), memungkinkan pemasaran produk dan layanan yang lebih baik (Moskowitz, 1972; Fombrun, 1996), menciptakan peluang yang tidak terduga (Fombrun et al., 2000), dan berkontribusi untuk memperoleh legitimasi sosial (Hawn et al., 2011). Studi terbaru yang dilakukan oleh: Pertama, Platonova et al. (2018) pada bank Islam di Gulf Cooperation Council (GCC) region periode 2000-2014; Kedua, Trihermanto \& Nainggolan (2020) pada perusahaan yang terdaftar di Indonesia antara tahun 2008 dan 2015, mereka melaporkan bahwa aktivitas dan pengungkapan CSR dapat meningkatkan profitabilitas perusahaan. Oleh karena itu, hipotesis yang diajukan adalah:

H4: Terdapat hubungan positif yang signifikan antara profitabilitas dan CSR.

\section{METODE PENELITIAN}

Penelitian ini dilakukan pada perusahaan sektor pertambangan kriteria syariah yang tercatat di Bursa Efek Indonesia selama periode 2015 hingga 2019. Rata-rata perusahaan pertambangan syariah yang memenuhi kriteria sampel per tahunnya adalah 29. Dengan demikian penelitian ini menggunakan 145 obervasi perusahaan-tahun.

Jenis dan proksi variabel

Variabel dependen adalah Corporate Social Responsibility Disclousure (CSRD) dan Profitabilitas diproksi Return on Assets (ROA). Variabel independen pada persamaan satu adalah corporate governance yang diproksi dengan Institutional Ownership (INOS), Board Directors Size (BDSZ), dan Independent Board of Commissioners (IBOC). Sedangkan, variabel independen pada persamaan dua adalah CSRD.

Definisi dan Operasionalisasi Variabel

Variabel CSRD Disclosure dengan definisi operasionalisasi sebagai berikut: 
1) Penentuan score CSRD menggunakan pendekatan dikotomi yaitu setiap item CSR dalam instrumen penelitian diberi nilai 1 jika diungkapkan, dan nilai 0 jika tidak. Score setiap item pengungkapan untuk masing-masing dimensi dijumlahkan dan dibagi score yang diharapkan, menggunakan rumus (Tan et al., 2016), berikut:

Exij

$\operatorname{CSRD}=\frac{}{n j}$

Keterangan:

CSRDj $=$ Corporate Social Responsibility Disclosure Index perusahaan $\mathrm{j}$.

$\mathrm{nj} \quad=$ Jumlah item untuk perusahaan $\mathrm{j}$.

$\sum \mathrm{xij} \quad=$ Total item yang diungkapkan dummy variabel: $1=$ jika item $\mathrm{i}$ diungkapkan; 0 = jika item i tidak diungkapkan.

2) Definisi operasionalisasi untuk variabel lainnya dikemukakan pada Tabel 3.1 berikut:

Tabel 1. Definisi Operasionalisasi Variabel

\begin{tabular}{lll}
\hline Variabel & Pengukuran & Referensi \\
\hline ROA & $\begin{array}{l}\text { Rasio earnings before interest and tax } \\
\text { terhadap total asset perusahaan. }\end{array}$ & $\begin{array}{l}\text { Aggarwal dan Padhan } \\
(2017), \text { Nurminda } \\
(2017) .\end{array}$ \\
Persentasi jumlah saham yang dimiliki & $\begin{array}{l}\text { institusi lain terhadap seluruh saham yang } \\
\text { beredar. }\end{array}$ & $\begin{array}{l}\text { Dewinta dan Setiawan } \\
\text { (2016), Aggarwal dan }\end{array}$ \\
IBOC & $\begin{array}{l}\text { Proporsi jumlah anggota dewan komisaris } \\
\text { independen terhadap seluruh anggota } \\
\text { dewan komisaris. }\end{array}$ & $\begin{array}{l}\text { Dewinta dan Setiawan } \\
\text { (2016), Rusmawati }\end{array}$ \\
BDSZ & $\begin{array}{l}\text { Logaritma dari jumlah semua anggota } \\
\text { dewan direksi yang dimiliki perusahaan. }\end{array}$ & \\
\hline
\end{tabular}

Sumber: Beberapa hasil penelitian sebelumnya.

\section{Metode Analisis Data}

Metode analisis data menggunakan path-analysis dengan memanfaatkan Partial Least Square-Structural Equation Modelling untuk menjawab hipotesis yang telah dirumuskan. Alat analisis yang dipergunakan yaitu software Warp-PLS versi 7.0.

Alat analisa PLS-SEM dipilih karena hubungan yang kompleks antara variabel laten dan indikator yang ada diestimasikan secara bersamaan. Model persamaan regresi yang dibangun untuk penelitian ini adalah sebagai berikut:

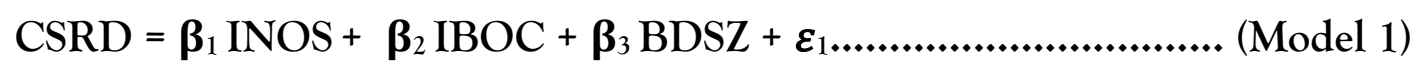




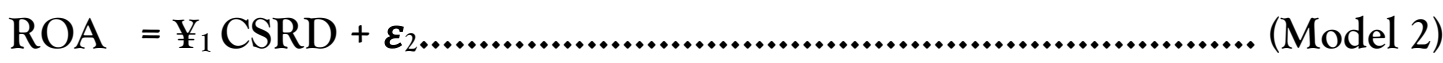

Dimana:

$\beta$ dan $¥$ adalah koefisien regresi untuk masing-masing persamaan struktural, $\varepsilon_{1}$ dan $\varepsilon_{2}$ adalah variabel lain yang tidak diidentifikasi.

\section{HASIL DAN PEMBAHASAN \\ Hasil}

Deskriptif statistik yang menyajikan nilai mean, maksimum, minimum, dan standar deviasi untuk masing-masing variabel ditunjukkan pada table 1 berikut.

Tabel 1. Statistik Deskriptif

\begin{tabular}{lrrrrr}
\hline & ROA & CSRD & INOS & BDSZ & IBOC \\
\hline Mean & 4.356 & 0.471 & 0.660 & 4.662 & 0.409 \\
Maximum & 122.415 & 0.658 & 0.974 & 8 & 1.000 \\
Minimum & -72.134 & 0.139 & 0.157 & 2 & 0.333 \\
Std. Dev. & 16.023 & 0.154 & 0.220 & 1.519 & 0.130 \\
\hline Observations & 145 & 145 & 145 & 145 & 145 \\
\hline \multicolumn{5}{c}{ Sumber: Laporan tahunan yang diolah }
\end{tabular}

Variabel ROA memiliki nilai mean $4.356 \%$, nilai maksimun $122.415 \%$, dan nilai minimum - 72.134\%. Variabel CSRD memiliki score mean 0.471, score maksimun 0.658, dan score minimum 0.139 . Variabel INOS memiliki nilai mean $0.660 \%$, nilai maksimun $0.974 \%$ yang berarti hampir semua saham perusahaan dimiliki institusi, dan nilai minimumnya $0.157 \%$. Variabel BDSZ memiliki nilai mean 4.662 atau mendekati 5 orang, nilai maksimun 8 menunjukkan paling banyak jumlah anggota dewan direktur adalah 8 orang, dan nilai minimumnya adalah 2 orang. Variabel IBOC memiliki proporsi rata-rata 0.409 orang, nilai proporsi maksimun sebesar 1.000 , yang berarti semua anggota dewan komisaris adalah independen dan nilai proporsi minimumnya adalah 0.130.

Tabel 2. Model Fit and Quality Indices

\begin{tabular}{|c|c|c|c|}
\hline Goodness of fit Index & Cut off Value & Result & Notes \\
\hline Average block VIF (AVIF) & Acceptable If $<=5$ & 1.025 & Acceptance \\
\hline $\begin{array}{l}\text { Average full collinearity VIF } \\
\text { (AFVIF) }\end{array}$ & Acceptable If $<=5$ & 1.112 & Acceptance \\
\hline Tenenhaus GoF (GoF) & $\begin{array}{l}\text { Small }>=0.1, \\
\text { Medium }>=0.25, \\
\text { Large }>=0.36\end{array}$ & 0.309 & $\begin{array}{l}\text { Acceptance } \\
\text { (Medium) }\end{array}$ \\
\hline Sympson's paradox ratio (SPR) & Acceptable If $>=0.7$ & 1.000 & Acceptance \\
\hline $\begin{array}{l}\text { R-squared contribution ratio } \\
\text { (RSCR) }\end{array}$ & Acceptable If $>=0.9$ & 1.000 & Acceptance \\
\hline Statistical suppression ratio (SSR) & Acceptable If $>=0.7$ & 1.000 & Acceptance \\
\hline
\end{tabular}




\begin{tabular}{lccc}
\hline Goodness of fit Index & Cut off Value & Result & Notes \\
\hline $\begin{array}{l}\text { Nonlinear bivariate causality } \\
\text { direction ratio (NLBCDR) }\end{array}$ & Acceptable If $>=0.7$ & 0.750 & Acceptance \\
Average path coefficient (APC) $=0.197, \mathrm{P}=0.004$ & & Significance \\
Average R-squared (ARS) $=0.095, \mathrm{P}=0.006$ & & Significance \\
Average adjusted R-squared (AARS) $=0.183, \mathrm{P}<0.001$ & Significance \\
\hline \multicolumn{2}{c}{ Sumber: Ouput model fit and quality indices aplikasi Wrap-PLS. }
\end{tabular}

Tabel 2 menunjukkan semua komponen dari pengukuran goodnes of fit dipenuhi secara sangat memadai. Ini dapat diketahui dari ouput model fit and quality indices yang ditunjukkan dengan nilai-nilai berikut: $P$ value untuk Average path coefficient (APC)= 0.197; $\mathrm{P}=0.004$, yang berarti lebih kecil dari 0.05. P value untuk Average R-squared $(A R S)=0.095, P=0.006$, ini berarti lebih kecil dari 0.05; P value untuk Average adjusted R-squared $(A A R S)=0.183, P<0.001$, ini berarti lebih kecil dari 0.01. Selain itu, nilai Average full collinearity VIF (AFVIF) yang dihasilkan adalah 1.112 lebih kecil dari nilai yang disyaratkan yaitu maksimal 5.00, ini berarti tidak ada masalah multikolinieritas antar indikator dan antar variabel eksogen. Model menghasilkan indeks GoF sebesar 0.309 lebih besar dari 0.25, ini berarti model fit dalam kategori medium. Indeks Sympson's paradox ratio (SPR) yang dihasilkan 1.000 lebih besar dari yang disyaratkan yaitu 0.700; Indeks R-squared contribution ratio (RSCR) yang dihasilkan 1.000 lebih besar dari yang disyaratkan 0.900; Indeks Statistical suppression ratio (SSR) yang dihasilkan 1.000 lebih besar dari yang disyaratkan 0.700; Indels Nonlinear bivariate causality direction ratio (NLBCDR) yang dihasilkan 0.750 , lebih besar dari yang disyarat-kan 0.700 , ini berarti tidak ada masalah kausalitas dalam model yang dibangun.

Tabel 3. Hubungan parsian antar variabel

\begin{tabular}{|c|c|c|c|c|c|c|}
\hline \multirow[b]{2}{*}{$\begin{array}{l}\text { Independent } \\
\text { Variable }\end{array}$} & \multicolumn{3}{|c|}{ Dependent Variable: CSRD } & \multicolumn{3}{|c|}{ Dependent Variables: ROA } \\
\hline & Coeff. & $\begin{array}{l}\text { Std. } \\
\text { Error }\end{array}$ & P Value & Coeff. & $\begin{array}{l}\text { Std. } \\
\text { Error }\end{array}$ & P Value \\
\hline INOS & 0.174 & 0.080 & $0.015^{* *}$ & 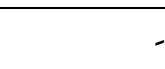 & - & \\
\hline IBOC & 0.142 & 0.080 & $0.040^{* *}$ & - & - & - \\
\hline BDSZ & 0.268 & 0.078 & $<0.001^{* * *}$ & - & - & . \\
\hline CSRD & - & - & - & 0.205 & 0.079 & $0.005^{* *}$ \\
\hline
\end{tabular}

Notes: ${ }^{* *}$ statistically significant at $5 \% ;{ }^{* * *}$ statistically significant at $1 \%$.

Tabel 3 menyajikan hasil analisis pengaruh variabel indpenden terhadap vareiabel dependen. Pengaruh INOS terhadap CSRD memiliki path coefficient 0.174 dengan P Value 0.015 , in berarti pengaruh yang positif dan signifikan, sehingga hipotesis 1 diterima. Pengaruh IBOC terhadap CSRD memiliki path coefficient 0.142 dengan P Value 0.040 , ini berarti pengaruh yang positif dan signifikan, sehingga hipotesis 2 diterima. Pengaruh BDSZ terhadap CSRD memiliki path coefficient 0.268 dengan P Value $<0.001$, ini berarti pengaruh yang positif dan signifikan, sehingga hipotesis 3 diterima. Pengaruh 
CSRD terhadap ROA memiliki path coefficient 0.205 dengan P Value 0.005 , ini berarti pengaruh yang positif dan signifikan, dengan demikian hipotesis 4 diterima.

Selanjutnya untuk memberikan gambaran yang lebih jelas, Gambar 1 berikut menyajikan hasil analisis pengaruh variabel independen terhadap variabel dependen.

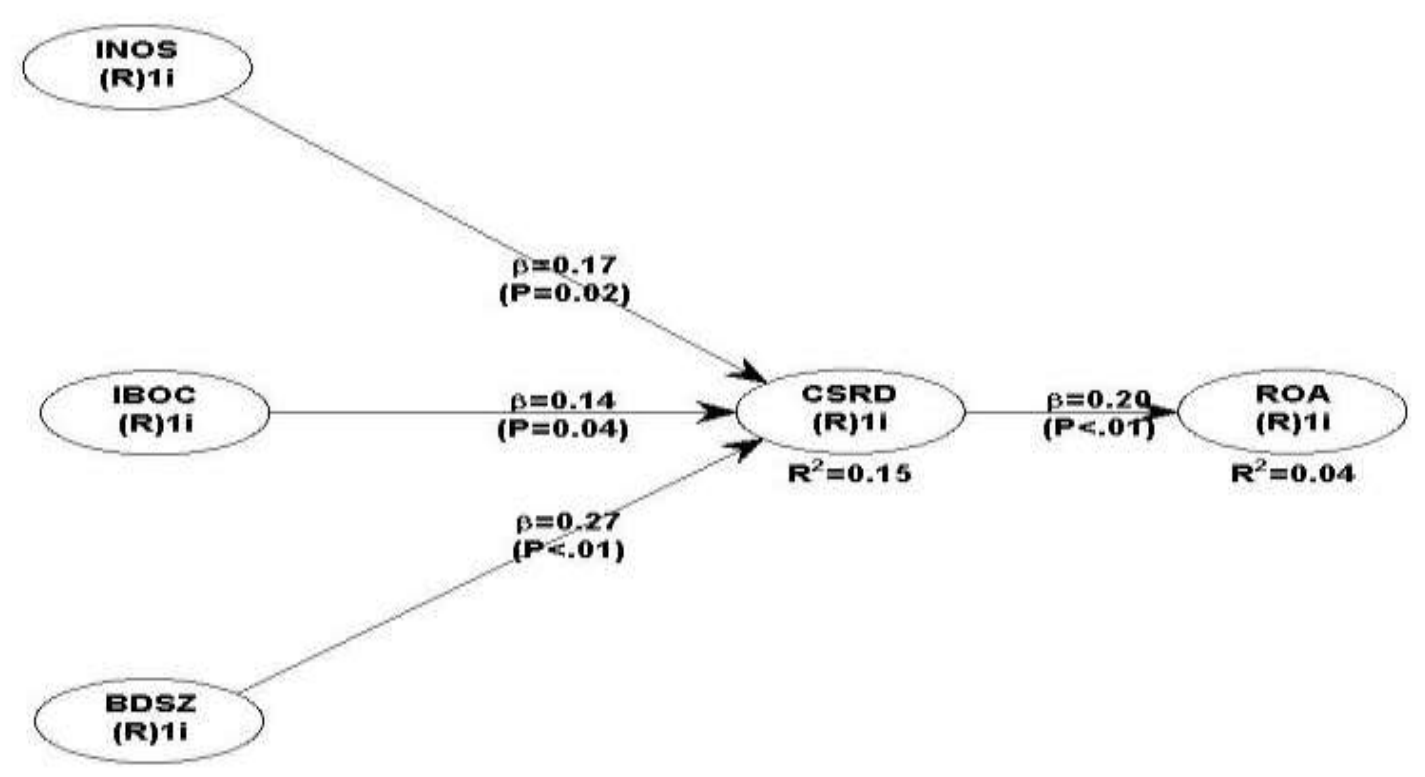

Sumber: Aplikasi Wrap-PLS versi 7.0

Gambar 1. Visualisasi hasil analisis antar variabel

\section{Pembahasan}

Hasil analisis memperlihatkan bahwa perusahaan pertambangan kriteria syariah yang sahamnya dimiliki lebih banyak oleh investor institusional (INOS) menunjukkan score CSRD yang lebih besar. Ini mengindikasikan bahwa investors institusional di perusahaan pertambangan kriteria Syariah telah menunjukkan peranya yang tinggi dalam upaya pengawasan yang lebih kuat dan ketat yang dapat menghambat perilaku oportunistik manajerial. Selain itu, investors institusional telah menggunakan hak mereka untuk memantau pengambilan keputusan operasional perusahaan, termasuk keputusan tentang aktivitas tanggung jawab sosial yang dilakukan oleh perusahaan (Meng \& Wang, 2020). Hasil penelitian ini sejalan dengan bukti empirik yang dilaporkan studi yang dilakukan oleh Meng \& Wang (2020) yang mengunakan sampel perusahaan yang tercatat di NYSE, AMEX dan NASDAQ. Hasil penelitian ini mendukung studi Trisnawati et al. (2019) yang menggunakan sampel seluruh perusahaan properti, real estate dan konstruksi bangunan yang terdaftar di Bursa Efek Indonesia selama periode 2013-2017.

Temuan empirik penelitian ini menunjukkan bahwa perusahaan pertambangan kriteria Syariah dengan ukuran dewan direksi (BDSZ) yang lebih besar memiliki CSRD yang lebih besar pula. Ini sejalan dengan perspektif teori ketergantungan sumber daya, 
yang menjelaskan bahwa ukuran dewan yang lebih besar cenderung memiliki dampak positif pada praktik pelaporan perusahaan karena anggota dewan dapat membawa berbagai nilai, pengetahuan, ide, dan perspektif ke organisasi mana pun (Pfeffer dan Salancik, 2003). Hasil penelitian ini sejalan dengan bukti empirik yang ditemukan oleh Nour et al. (2019) yang mengunakan sampel perusahaan publik Yordania periode 2010. 2014. Selain itu, temuan penelitian ini mendukung studi Tran et al. (2020) yang meggunakan sampel semua bank komersial Vietnam periode 2015-2019. Namun, hasil penelitian ini berbeda dengan studi yang dilakukan oleh Orazalin (2019) menggunakan sampel semua bank umum yang terdaftar di Bursa Efek Kazakhstan periode 2010-2016. Mereka membuktikan bahwa ukuran dewan tidak terkait secara signifikan dengan CRSD.

Hasil menunjukkan bahwa perusahaan pertambangan kategori Syariah dengan proporsi dewan komisaris (IBOC) yang lebih besar memiliki CSRD yang lebih besar pula. Temuan ini mendukung perspektif teori pemangku kepentingan, yang menjelaskan bahwa dewan independen memiliki dorongan untuk mengejar kepentingan semua pemangku kepentingan dengan memaksa manajemen untuk mengungkapkan lebih banyak informasi terkait keberlanjutan dan untuk meningkatkan citra perusahaan dengan berfokus pada isu-isu lingkungan dan sosial (Rao et a., 2012). Hubungan positif dewan independen dengan corporate social responsibility disclousure (CSRD) juga dilaporkan oleh hasil penelitian Celentano et al. (2020) menggunakan sampel sebanyak 119 perusahaan non-keuangan yang terdaftar di Bursa Efek Italia periode 2017. Namun demikian, hasil ini berbeda dengan studi Orazalin (2019) di semua bank umum yang terdaftar di Bursa Efek Kazakhstan periode 2010-2016, yang membuktikan bahwa dewan independen tidak terkait secara signifikan dengan score CRSD.

Hasil analisis menunjukkan bahwa perusahaan pertambangan kriteria Syariah yang mengungkapkan aktivitas CSRD yang lebih besar terkait secara signifikan dengan profitabilitas (ROA) yang lebih tinggi. Hasil ini mendukung Cochran \& Wood (1984) yang mengungkapkan bahwa melakukan kegiatan CSR dapat memiliki efek positif pada kinerja perusahaan dengan menyediakan akses yang lebih baik ke sumber daya yang berharga. Selain itu, aktivitas CSRD dapat menarik dan mempertahankan karyawan berkualitas lebih tinggi (Turban \& Greening, 1997; Greening dan Turban , 2000), memungkinkan pemasaran produk dan layanan yang lebih baik (Moskowitz, 1972; Fombrun, 1996), menciptakan peluang yang tidak terduga (Fombrun et al., 2000), dan berkontribusi untuk memperoleh legitimasi secara sosial (Hawn et al., 2011). Selanjutnya, hasil ini sejalan dengan bukti empirik yang dilaporkan oleh dua penelitian sebelumnya, yaitu Platonova et al. (2018) menggunakan sampel bank Islam di Gulf Cooperation Council (GCC) region selama periode 2000-2014, dan Trihermanto \& Nainggolan (2020) menggunakan sampel 527 perusahaan yang terdaftar di Indonesia atau sebanyak 923 observasi tahun perusahaan di Indonesia antara tahun 2008 dan 2015.

\section{PENUTUP}

\section{Kesimpulan}

Penelitian ini menguji dampak Corporate Governance pada Social Responsibility Disclosure (CSRD) dan pengaruh CSRD terhadap Profitabilitas (ROA) pada Perusahaan 
Pertambangan Syariah Di Bursa Efek Indonesia. Berdasarkan hasil analisis data dapat disimpulkan bahwa: Perusahaan pertambangan kriteria Syariah yang memiliki ukuran dewan yang lebih besar menunjukkan CSRD yang lebih besar; Perusahaan pertambangan kriteria Syariah yang memiliki proporsi dewan independen yang lebih besar menunjukkan CSRD yang lebih besar; Perusahaan pertambangan kriteria Syariah yang sahamnya dipegang oleh investor institusional dengan pesentase yang lebih besar memiliki CSRD yang lebih besar. Terakhir, perusahaan pertambangan kriteria Syariah yang memiliki CSRD yang lebih besar menunjukkan capaian ROA yang lebih besar. Dengan demikian, hasil penelitian ini berkontribusi pada pengembangan teori corporate governance dalam hubungannya dengan pengungkapan aktivitas CSR dan hubungan CSRD dengan Profitabilitas, untuk perusahaan pertambangan kriteria Syariah di Indonesia.

Hasil penelitian ini diharapkan dapat digunakan selain oleh perusahaan pertambangan yang sudah listing di bursa saham, juga dapat digunakan oleh perusahaan yang berskala lebih kecil seperti perusahaan tambang Badan Usaha Milik Daerah (BUMD) bahkan perusahaan tambang Badan Usaha Milik Desa (BUMDES). Agar perusahan-perusahaan pertambangan tersebut dapat mempraktekkan CSR terutama terhadap lingkungan secara bertanggung jawab. Dengan demikian prinsip good mining practices dapat dipenuhi dan perusahaan pertambangan di Indonesia menjadi pendukung kelestarian alam .

\section{Saran}

Penelitian ini menyarankan kepada manajemen perusahaan pertambangan kriteria syariah di Indonesia untuk tetap mempertahankan ukuran dewan direksi, proprosi dewan komisaris independen, dan persentasi kepemilikan saham oleh investors institusional, serta meningkatkannya secara proporsional. Selain itu, menyarankan kepada investors agar menanamkan dana mereka pada perusahaan pertambangan kriteria Syariah yang memiliki score CSRD yang besar. Selanjutnya, untuk agenda penelitian yang akan datang disarankan untuk membandingkannya perusahaan pertambangan konvensional.

\section{DAFTAR PUSTAKA}

Adeneye, Y., \& Ahmed, M. (2015). Corporate social responsibility and company performance. Journal of Business Studies Quarterly, 7(1), 151.

Al-ahdal, W. M., Alsamhi, M. H., Tabash, M. I., \& Farhan, N. H. S. (2020). The impact of corporate governance on financial performance of Indian and GCC listed firms: An empirical investigation. Research in International Business and Finance, 51(August 2019). https://doi.org/10.1016/j.ribaf.2019.101083

Aras, G., \& Kutlu, A. O. (2010). Managing corporate performance: Investigating the relationship between corporate social responsibility and financial performance in emerging markets. International Journal of Productivity and Performance Management, 59(3), 229-254.

Artiach, T., Lee, D., Nelson, D., \& Walker, J. (2010). The determinants of corporate 
sustainability performance. Accounting and Finance, 50(1), 31-51. https://doi.org/10.1111/j.1467-629X.2009.00315.x

Aupperle, K. E., Carroll, A. B., \& Hatfield, J. D. (1985). An Empirical Examination of the Relationship between Corporate Social Responsibility and Profitability. Business and Professional Ethics Journal, 28(2), 446-463. https://doi.org/10.5840/bpej199514214

Backhaus, K. B., Stone, B. A., \& Heiner, K. (2002). Exploringthe Relationship Between Corporate Social Performance and Employer Attractiveness. Business $\mathcal{E}$ Society, 41(3), 292-318. https://doi.org/10.1177/0007650302041003003

Barako, D. G., \& Brown, A. M. (2008). Corporate social reporting and board representation: Evidence from the Kenyan banking sector. Journal of Management and Governance, 12(4), 309-324. https://doi.org/10.1007/s10997-008-9053-x

Barnea, A., \& Rubin, A. (2010). Corporate Social Responsibility as a Conflict Between Shareholders. Journal of Business Ethics, 97(1), 71-86. https://doi.org/10.1007/s10551-010-0496-z

Brammer, S., \& Millinhton, A. (2008). Does it pay to be different? An analysis of the relationship between corporate social and financial performance. Strategic Management Journal, 29(March), 1325-1343. https://doi.org/10.1002/smj

Celentano, A., Lepore, L., Pisano, S., D’Amore, G., \& Alvino, F. (2020). The joint effect of board independence and CSR committee on CSR disclosure: Evidence from Italian listed companies. Corporate Ownership and Control, 17(4, Special Issue), 319328. https://doi.org/10.22495/cocv17i4siart9

Chen, R. C. Y., \& Lee, C. H. (2017). The influence of CSR on firm value: an application of panel smooth transition regression on Taiwan. Applied Economics, 49(34), 34223434. https://doi.org/10.1080/00036846.2016.1262516

Chen, T., Dong, H., \& Lin, C. (2020). Institutional shareholders and corporate social responsibility. Journal of Financial Economics, 135(2), 483-504. https://doi.org/10.1016/j.jfineco.2019.06.007

Cormier, D., Magnan, M., \& Van Velthoven, B. (2005). Environmental disclosure quality in large German companies: Economic incentives, public pressures or institutional conditions? European Accounting Review, 14(1), 3-39. https://doi.org/10.1080/0963818042000339617

Cui, J., Jo, H., \& Na, H. (2018). Does Corporate Social Responsibility Affect Information Asymmetry? Journal of Business Ethics, 148(3), 549-572. https://doi.org/10.1007/s10551-015-3003-8

de Villiers, C., Naiker, V., \& van Staden, C. J. (2011). The effect of board characteristics on firm environmental performance. Journal of Management, 37(6), 1636-1663. https://doi.org/10.1177/0149206311411506

Derksen, F., Bensing, J., \& Lagro-Janssen, A. (2013). Effectiveness of empathy in general practice: A systematic review. British Journal of General Practice, 63(606), 76-84. https://doi.org/10.3399/bjgp13X660814

Donnelly, R., \& Mulcahy, M. (2008). Board structure, ownership, and voluntary disclosure in Ireland. Corporate Governance: An International Review, 16(5), 416-429. 
https://doi.org/10.1111/j.1467-8683.2008.00692.x

Epstein, M. J., \& Freedman, M. (1994). Social Disclosure and the Individual Investor. Accounting, Auditing $\mathcal{E}$ Accountability Journal, 7(4), 94-109. https://doi.org/10.1108/09513579410069867

Esa, E., \& Ghazali, N. A. M. (2012). Corporate social responsibility and corporate governance in Malaysian government-linked companies. Corporate Governance (Bingley), 12(3), 292-305. https://doi.org/10.1108/14720701211234564

Ghabayen, M. A., Mohamad, N. R., \& Ahmad, N. (2016). Board characteristics and corporate social responsibility disclosure in the jordanian banks. Corporate Board: Role, Duties and Composition, 12(1CONT1), 84-99. https://doi.org/10.22495/cbv12i1c1art2

Haniffa, R. M., \& Cooke, T. E. (2005). The impact of culture and governance on corporate social reporting. Journal of Accounting and Public Policy, 24(5), 391-430. https://doi.org/10.1016/j.jaccpubpol.2005.06.001

Hossain, M., \& Reaz, M. (2007). The determinants and characteristics of voluntary disclosure by Indian banking companies. Corporate Social Responsibility and Environmental Management, 14(5), 274-288. https://doi.org/10.1002/csr.154

Jaffar, R., Riduan, M., \& Abdul, C. (2007). MALAYSIAN ACCOUNTING. 6(2).

Jensen, M. C. (2002). VALUE MAXIMIZATION, STAKEHOLDER THEORY, AND THE CORPORATE OBJECTIVE FUNCTION Michael C. Jenseti. Business Ethics Quarterly, 12(2), 235-256.

Jizi, M. I., Salama, A., Dixon, R., \& Stratling, R. (2014). Corporate Governance and Corporate Social Responsibility Disclosure: Evidence from the US Banking Sector. Journal of Business Ethics, 125(4), 601-615. https://doi.org/10.1007/s10551-013. 1929-2

Kansal, M., Joshi, M., \& Batra, G. S. (2014). Determinants of corporate social responsibility disclosures: Evidence from India. Advances in Accounting, 30(1), $217-$ 229. https://doi.org/10.1016/j.adiac.2014.03.009

Khan, H. U. Z. (2010). The effect of corporate governance elements on corporate social responsibility (CSR); reporting: Empirical evidence from private commercial banks of Bangladesh. International Journal of Law and Management, 52(2), 82-109. https://doi.org/10.1108/17542431011029406

Khlif, H., \& Souissi, M. (2010). The determinants of corporate disclosure: A metaanalysis. International Journal of Accounting $\mathcal{E}$ Information Management, 18(3), 198-219. https://doi.org/10.1108/18347641011068965

Kilic, M., Kuzey, C., \& Uyar, A. (2015). The Impact of Ownership and Board Structure on Corporate Social Responsibility (CSR) Reporting in the Turkish Banking Industry The Relationship between Governance Indicators and Tax Evasion in the EU View project Earnings management View project Merve K1l. Corporate Governance International Journal of Business in Society. http://dx.doi.org/10.1108/CG-02-20140022

Kim, I., Wan, H., Wang, B., \& Yang, T. (2019). Institutional investors and corporate 
environmental, social, and governance policies: Evidence from toxics release data. Management Science, 65(10), 4901-4926. https://doi.org/10.1287/mnsc.2018.3055 Mahoney, L., \& Roberts, R. W. (2007). Corporate social performance, financial performance and institutional ownership in Canadian firms. Accounting Forum, 31(3), 233-253. https://doi.org/10.1016/j.accfor.2007.05.001

McWilliams, A., \& Siegel, D. (2000). Corporate social responsibility and financial performance: Correlation or misspecification? Strategic Management Journal, 21(5), 603-609. https://doi.org/10.1002/(SICI)1097-0266(200005)21:5<603::AID$\mathrm{SMJ} 101>3.0 . \mathrm{CO} ; 2-3$

Meng, Y., \& Wang, X. (2020). Do institutional investors have homogeneous influence on corporate social responsibility? Evidence from investor investment horizon. Managerial Finance, 46(3), 301-322. https://doi.org/10.1108/MF-03-2019-0121

Nguyen, P., \& Nguyen, A. (2015). The effect of corporate social responsibility on firm risk. Social Responsibility Journal, 11(2), 324-339. https://doi.org/10.1108/SRJ-082013-0093

Nour, A. I., Sharabati, A.-A. A., \& Hammad, K. M. (2019). Corporate Governance and Corporate Social Responsibility Disclosure. International Journal of Sustainable Entrepreneurship and Corporate Social Responsibility, 5(1), 20-41. https://doi.org/10.4018/ijsecsr.2020010102

Oeyono, J., Samy, M., \& Bampton, R. (2011). An examination of corporate social responsibility and financial performance. Journal of Global Responsibility, 2(1), 100112. https://doi.org/10.1108/20412561111128555

Oh, W. Y., Chang, Y. K., \& Martynov, A. (2011). The Effect of Ownership Structure on Corporate Social Responsibility: Empirical Evidence from Korea. Journal of Business Ethics, 104(2), 283-297. https://doi.org/10.1007/s10551-011-0912-z

Orazalin, N. (2019). Corporate governance and corporate social responsibility (CSR) disclosure in an emerging economy: evidence from commercial banks of Kazakhstan. Corporate Governance (Bingley), 19(3), 490-507. https://doi.org/10.1108/CG-09. 2018-0290

Panda, B., \& Leepsa, N. M. (2017). Agency theory: Review of theory and evidence on problems and perspectives. Indian Journal of Corporate Governance, 10(1), 74-95. https://doi.org/10.1177/0974686217701467

Platonova, E., Asutay, M., Dixon, R., \& Mohammad, S. (2018). The Impact of Corporate Social Responsibility Disclosure on Financial Performance: Evidence from the GCC Islamic Banking Sector. Journal of Business Ethics, 151(2), 451-471. https://doi.org/10.1007/s10551-016-3229-0

Rahman, M., Rodríguez-Serrano, M. Á., \& Lambkin, M. (2017). Corporate social responsibility and marketing performance: The moderating role of advertising intensity. Journal of Advertising Research, 57(4), 368-378. https://doi.org/10.2501/JAR-2017-047

Rao, K. K., Tilt, C. A., \& Lester, L. H. (2012). Corporate governance and environmental reporting: An Australian study. Corporate Governance: The International Journal of Business in Society, 12(2), 143-163. https://doi.org/10.1108/14720701211214052 
Reddy, K., \& Gordon, L. W. (2010). The effect of sustainability reporting on financial performance: An empirical study using listed companies. Journal of Asia Entrepreneurship and Sustainability, 6(2), 19-42.

Sabbaghi, O., \& Xu, M. (2013). ROE and Corporate Social Responsibility: Is There a Return On Ethics? Journal of Accounting and Finance, 13(4), 82-95. http://search.proquest.com/docview/1502615618? accountid=13250

Said, R., Zainuddin, Y., \& Haron, H. (2009). The relationship between corporate social responsibility disclosure and corporate governance characteristics in Malaysian public listed companies. Social Responsibility Journal, 5(2), 212-226. https://doi.org/10.1108/17471110910964496

Servaes, H., \& Tamayo, A. (2013). The Impact of Corporate Social Responsibility on Firm Value: The Role of Customer Awareness. Management Science, 59(5), 1045-1061. https://doi.org/10.13106/jafeb.2021.vol8.no3.0209

Shafiqur, R. (2011). Evaluation of Definitions: Ten Dimensions of Corporate Social Responsibility. World Review of Business Research, 1(1), 166-176.

Skovgaard, J. (2014). European union's policy on corporate social responsibility and opportunities for the maritime industry. International Journal of Shipping and Transport Logistics, 6(5), 513-530. https://doi.org/10.1504/IJSTL.2014.064572

Tran, Q. T., Lam, T. T., \& Luu, C. D. (2020). Effect of Corporate Governance on Corporate Social Responsibility Disclosure: Empirical Evidence from Vietnamese Commercial Banks*. Journal of Asian Finance, Economics and Business, 7(11), 327-333. https://doi.org/10.13106/jafeb.2020.vol7.no11.327

Trihermanto, F., \& Nainggolan, Y. A. (2020). Corporate life cycle, CSR, and dividend policy: empirical evidence of Indonesian listed firms. Social Responsibility Journal, 16(2), 159-178. https://doi.org/10.1108/SRJ-09-2017-0186

Trisnawati, R., Sasongko, N., \& Indrawati, L. (2019). Good Corporate Governance , Corporate Social Responsibility Disclosure, and Firm Value. International Summit on Science Technology and Humanity (ISETH2019), 4(2), 479-489.

Waddock, S. A., \& Graves, S. B. (1997). The Corporate Social Performance-Financial Performance Link. Stategic Manajemen Journal, 18(4), 303-319. 